\title{
No takers so far for NASA science institutes
}

Washington. A full year after announcing plans to transfer some of its research operations to privatized science institutes, the US National Aeronautics and Space Administration (NASA) has yet to find anyone willing to sponsor an astrobiology institute associated with the agency's Ames Research Center in San Francisco.

Furthermore, although the team responsible for setting up the institutes issued its final report last week, critics charge that the overall concept still lacks detail. "We still don't have enough specific information to make any informed judgement," says Mary Jane Osborn of the University of Connecticut Health Center, a member of the National Research Council's Space Studies Board, which was briefed on the plan last week.

The science institutes were initially conceived to save money. But they are now seen as a way for the space agency to improve the quality of its science and strengthen its ties with the outside research community (see Nature 378, 121; 1995).

The NASA study team headed by Alphonso Diaz, now deputy director of the Goddard Space Flight Center, recommended last November that three of the 11 proposed institutes were ready for implementation: a biomedical research institute affiliated with the Johnson Space Center in Houston; the Ames astrobiology institute; and a microgravity institute at the Lewis Research Center in Cleveland, Ohio.

Of the three, planning for the biomedical institute has progressed the furthest. Diaz says he hopes to hold a 'bidders' conference' this spring for potential sponsors in the university and non-profit sector. But many questions remain, including whether institutes must be located in the same area as the NASA centre, and what the chain of command would be between NASA headquarters, the institute, and Johnson. At present the relationship is fuzzy, says Osborn.

Particularly worrying is the question of peer review. Life science at NASA, plagued in the past by charges of shoddy research, has only recently begun to shed that image thanks to rigorous peer review procedures instituted at the agency's headquarters. To shift such responsibility back to the centres or to an institute would be "a very unacceptable outcome", says Osborn.

At Ames, hundreds of scientists currently employed by the federal government would probably be transferred to the new institute. NASA has proposed that new legislation should protect these civil servants' benefits, preventing them from being barred from working for the institutes by laws restricting post-government employment.

To do this, the agency has proposed language to be included in its 1997 authorization bill, and Robert Walker (Republican, Pennsylvania), chairman of the House
Science Committee, has also included a provision easing employment restrictions in the draft of a space commercialization bill he plans to introduce later this year.

But personnel issues are not the only reason that no-one is beating down NASA's door to take on the astrobiology institute at Ames. The work of the institute would cut across three disciplines: space science, life science and Earth science. Some potential sponsors have expressed interest in pieces of each, says Diaz; but "very seldom did we find that people were interested in the full breadth of what we're offering".

NASA's answer is to hold a workshop in

\section{Untethered satellite still produced data}

Munich. Silvano Casini, chief administrator of the Italian Space Agency (ASI), last week defended the agency's ill-fated tethered satellite mission. Despite the dramatic loss of the satellite after its tether snapped as it was being unreeled from the space shuttle, Casini said that many of the scientific aims of the mission had been achieved.

But the bad publicity remains a further unwelcome burden for ASI - as well as its partner in the mission, the US National Aeronautics and Space Administration (NASA) - just as the Italian agency is struggling to throw off an image of inefficiency and wastefulness.

The main aim of the mission was to investigate the creation of an electrical current along a $20-\mathrm{km}$ conductive tether, attached at one end to the space shuttle, as it was dragged through magnetic fields by a satellite moving in a slightly higher orbit, with the electrical circuit being closed by electron guns in the shuttle's payload bay discharging the electricity back into the ionosphere.

At least the test of this idea was successful. Nearly the whole length of the tether had already been unwound, at 2.2 metres per second, before it snapped within the deployment boom, giving enough time for scientists to observe the predicted flow of electricity. A voltage of 3,500 volts and a current of $480 \mathrm{~mA}$ were measured shortly before the break.

A second aim, to test the dynamic behaviour in orbit of a large rigid system $20 \mathrm{~km}$ in length, failed. But there was some success with other experiments conducted by the satellite not directly related to the tether, exploiting instead the satellite's position in a little-explored orbit which is unstable for free-flying satellites. As radio contact with the satellite was restored after the tether had broken, and was maintained for a the summer to show off the range of science operations at Ames. While Diaz still hopes to sell the whole facility to a single buyer, NASA will consider selling individual lots. "We don't want to put out a requirement that nobody responds to," he says. "But we obviously don't want to break it up into so many small pieces that it creates a bureaucracy to integrate it all."

In short, the agency is trying to execute something that has never been tried before. "I don't think it's a matter of NASA trying to evade the questions," says one Congressional staff member. "I really don't think they know at this point."

Tony Reichhardt

few hours a day for four days before the satellite's batteries died, some data describing the plasma environment in the upper ionosphere magnetic field were successfully generated.

Yet despite the relative scientific success of the mission, and uncertainty about how - and if - blame should be allocated, the perceived failure of the experiment in the eyes of the Italian public is a further cross for ASI to bear at a time when it is under considerable political pressure. Indeed, some politicians immediately questioned the value of Italy's space programme, given the country's major economic difficulties.

ASI, long criticized for its inefficiency, is in the hands of a temporary administration, whose mandate to restructure the agency expires in June. A new law governing its structure and activities was expected to be in place by then. But the recent call for elections in late April means that this will be virtually impossible to achieve.

Meanwhile, ASI may have to face yet another problem. Its X-ray satellite, SAX, which has been subject to continual and controversial delays, is being prepared for launch on 29 April. But a group of specialists from the European Space Agency, which has been contracted to review the readiness of the ground segment of the mission, is expected to report this week that this part of the mission could be significantly improved.

ASI has to decide whether to go ahead with the launch without the improvements, or to delay the mission until the next possible launch date in October 1997, eight years later than originally planned. Italian scientists have continually criticized the project for its escalating costs and delays, which they claim, have made its science outdated.

Alison Abbott 